\title{
Influence of Simvastatin on Bone Regeneration of Tibial Defects and Blood Cholesterol Level in Rats
}

\author{
Ana Lia ANBINDER ${ }^{1}$ \\ Juliana Campos JUNQUEIRA² \\ Maria Nadir G. MANCINI ${ }^{2}$ \\ Ivan BALDUCCI ${ }^{3}$ \\ Rosilene Fernandes da ROCHA ${ }^{2}$ \\ Yasmin Rodarte CARVALHO ${ }^{2}$
}

\author{
${ }^{1}$ Department of Dentistry, University of Taubaté, Taubaté, SP, Brazil \\ ${ }^{2}$ Department of Biosciences and Oral Diagnosis; ${ }^{3}$ Department of Social Dentistry and Pediatric Clinics, \\ School of Dentistry of São José dos Campos, São Paulo State University, São José dos Campos, SP, Brazil
}

\begin{abstract}
The purpose of this study was to evaluate the effects of simvastatin, by oral or subcutaneous administration, on tibial defects regeneration and blood cholesterol level in rats. A surgical defect was made on the right tibia of 40 male animals assigned to 4 groups $(\mathrm{n}=10)$, based on two routes of administration and on the use or not of simvastatin: subcutaneous injection of simvastatin $(7 \mathrm{mg} / \mathrm{kg})$ (group AT) or only the vehicle of drug suspension (group AC), above the defect area, for 5 days; and $20 \mathrm{mg} / \mathrm{kg}$ of simvastatin macerated on water (group BT) or only water (group BC), orally, daily, during the whole observation period. The animals were sacrificed after 15 or 30 days, when blood samples were analyzed to check plasma cholesterol levels. Tibiae were removed and, after decalcification and routine laboratorial processing, histological and histomorphometrical analyses were carried out. ANOVA was used for statistical analysis at 5\% signficance level. The histological and histomorphometrical analyses showed significant differences only between the experimental periods $(\mathrm{p}<0.05)$. Animals sacrificed after 30 days showed better bone repair $(\mathrm{p}<0.05)$. There was no statistically significant difference $(\mathrm{p}>0.05)$ for blood cholesterol levels between the groups. In conclusion, simvastatin administration either orally or subcutaneously did not improve bone repair of experimental tibial defects and did not alter blood cholesterol levels in rats.
\end{abstract}

Key Words: bone regeneration, simvastatin, cholesterol, rats.

\section{INTRODUCTION}

The bone tissue has a unique potential for restoring its original structure completely after injuries. However, large defects caused by trauma, cysts, neoplasms, infections or congenital malformations may not regenerate spontaneously and the use of surgical or pharmacological measures is required for complete regeneration. Bone deficiencies are of major concern and affect therapies in all dental and medical fields. Because of the limitations of current bone grafting methods, alternative methods for repairing bone defects are needed. Future bone defect treatment may rest on the use of inductive materials, like recombinant bone morphogenetic proteins, which have been added as adjuncts to already known biomaterials with success.

Statins or 3-hydroxy 3-methylglutaryl coenzyme A reductase (HMG-CoA reductase) inhibitors have been widely used over the last decade for the treatment of hypercholesterolemia. HMG-CoA reductase, which converts HMG-CoA to mevalonate, is the rate-limiting enzyme in the synthesis of cholesterol. Competitive inhibition of this enzyme by statins decreases intracellular cholesterol biosynthesis, which leads to transcriptionally upregulated production of microsomal HMG-CoA reductase and low-density lipoprotein (LDL) cell surface receptors (1). Due to upregulation of HMG-CoA reductase, cholesterol synthesis is slightly decreased, but there is a stimulation of low-density lipoprotein cholesterol removal from blood, which reduces plasma

Correspondence: Profa. Dra. Ana Lia Anbinder, Rua dos Operários, n. 9, Centro, 12020-270 Taubaté, SP, Brasil. Tel: +55-12-3625-4142. Fax: +55-12-3632-4968. e-mail: anaanbinder@hotmail.com 
cholesterol levels (2).

Recent studies have shown that these drugs are also capable of stimulating bone formation by increasing expression of BMP-2 (3). Because of this, it is believed that statins, if selectively target to bone, might be useful for fractures and osteoporosis treatment (3). These facts raised much interest in the scientific world and many studies were made, suggesting that HMG-CoA reductase inhibitors may increase bone density and decrease risk of fractures (4).

Because of its high hepatic targeting property, statins do not accumulate in bone, like bisphosphonates do (5). To make possible the use of HMG-CoA reductase inhibitors as therapy for bone pathologies, it is important to find a way of using these drugs that maximize their action on bone, without harming their cardiovascular benefits.

Therefore, this study evaluated the effects of simvastatin, a drug of the statin group, by oral or subcutaneous administration, on bone regeneration of tibial defects and blood cholesterol levels in rats.

\section{MATERIAL AND METHODS}

Forty male rats (Rattus norvegicus, albinus, Wistar) weighing approximately $400 \mathrm{~g}$ were used. The animals were allowed free access to water and standard laboratory food pellets. The study design was approved by the Ethics in Research Committee of the School of Dentistry of São José dos Campos, São Paulo State University, Brazil.

A monocortical bone defect on the right tibia was created in all animals. Anesthesia was induced intramuscularly with a $0.1 \mathrm{~mL} / 100 \mathrm{~g}$ dose injection of a mixture of xylazine (Rompun ${ }^{\circledR}$; Bayer, São Paulo, SP, Brazil) and ketamine (Francotar ${ }^{\circledR}$; Virbac, Roseira, SP, Brazil) at 1:0.5 ratio $\mathrm{mL}$. The overlying skin of the right tibia was shaved and disinfected with iodated alcohol. After this, a $1.5 \mathrm{~cm}$ skin and muscle incision was made to expose the bone surface of the middle third of the tibia (Fig. 1A), where, on the wider region, a monocortical defect was created. A 2-mm diameter trephine and a size 8 stainless steel dental burs were used on a low-speed handpiece (Aseptico; Woodinville, WA, USA), under constant saline irrigation to create an oval bone defect measuring approximately $2.5 \mathrm{~mm}$ in width and $3 \mathrm{~mm}$ in length, with the cortical thickness (Fig. 1B). The muscular layer was sutured with resorbable \#4.0 catgut
(Cirumédica, Cotia, SP, Brazil) and the skin was sutured with interrupted \#4.0 silk suture (Ethicon/Johnson \& Johnson, São José dos Campos, SP, Brazil).

To prepare the drug for subcutaneous injection, simvastatin (Galena, Campinas, SP, Brazil) was dissolved in dymethylsulfoxide (DMSO; Sigma Chemical Co., St Louis, MO, USA) at a ratio of $112 \mathrm{mg} / \mathrm{mL}$. Next, $0.1 \%$ bovine serum albumin (BSA; Sigma Chemical Co.) diluted in phosphate-buffered saline (PBS) was added to the mixture until final DMSO concentration reached $4 \%$. To prepare the vehicle for injection in the control animals, $4 \%$ DMSO was dissolved in a solution of $0.1 \%$ bovine serum albumin/PBS. Oral suspension was prepared by macerating $20 \mathrm{mg} / \mathrm{kg}$ of simvastatin (Sinvascor ${ }^{\circledR} 20$ mg; Baldacci, São Paulo, SP, Brazil) in filtered water at a ratio of $40 \mathrm{mg} / \mathrm{mL}$.

The animals were assigned to 4 groups $(n=10)$, based on two routes of administration (subcutaneous injection or oral) and on the use or not of simvastatin: A-treated (AT): the rats received a subcutaneous injection of simvastatin suspension above the defect region 3 times a day during 5 days postoperatively (the final dose was $7 \mathrm{mg} / \mathrm{kg} /$ day); A-control (AC): the animals received only the corresponding volume of vehicle of suspension used in group AT, above the defect region, 3 times a day during 5 days postoperatively; B-treated (BT): the animals received $20 \mathrm{mg} / \mathrm{kg} /$ day of simvastatin orally, daily, from surgery until sacrifice day; B-control (BC): the animals received only the corresponding

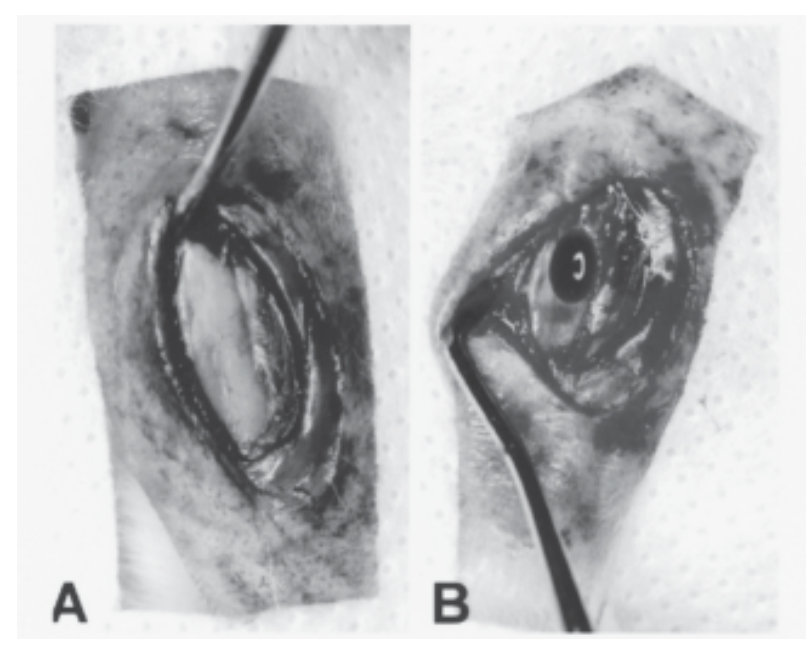

Figure 1. Detail of the surgical proceedure. (A) Bone exposure; (B) Bone defect. 
volume of filtered water used in group BT, orally, daily, from surgery until sacrifice day.

Doses used in groups AT and AC were divided in 3 fractions because it was not possible to inject the total volume subcutaneously ( $7 \mathrm{mg} / \mathrm{kg} /$ day) in one dose. Dose schedule and route of administration were based on Mundy et al. (3).

Five rats per group were sacrificed 15 days postoperatively (groups AT15, AC15, BT15, BC15) and the remaining animals 30 days after surgery (groups AT30, AC30, BT30, BC30). At the moment of sacrifice, the animals were put under the same anesthesia as at time of surgery and $2 \mathrm{~mL}$ of blood from the cava vein were obtained using syringes with heparin (Liquemine; Roché, Rio de Janeiro, RJ, Brazil). Animals were euthanized by decapitation and the right tibiae were removed and fixed in 10\% buffered formalin (Labsynth, Diadema, SP, Brazil).

Total cholesterol level on plasma samples was analyzed by modified Huang's method, based on the Liebermann-Buchard reaction (6). In this chemical method, cholesterol combines with a cromogenic reagent and a green substance is produced. The color intensity of the substance is measured by a spectrophotometer.

The tibiae were decalcified in a $20 \%$ formic acid aqueous solution (Merck, Darmstadt, Germany) and cross-sectioned at the central region of bone defect. The specimens were embedded in paraffin parallel to the sectioned surface and the blocks were cut into 8 fivemicrometer-thick semi-serial sections ( $15 \mu \mathrm{m}$ between each level). After staining with hematoxylin and eosin (HE), the specimens were evaluated by light microscopy.

The percentage of reossification of the bone defect center was histomorphometrically evaluated by point-counting planimetry. For this procedure, a grid of parallel equidistant test lines with 72 cross-points was used. Using an X20 objective, the grid was placed over the entire defect thickness. The proportion of intersection points between lines of a graticule lying over a structure is equal to the area proportion of that structure in the section (7). It was considered the percentage of all points over cancellous or cortical bone matrix and osteocyte lacunae to total number of points over bone defect. Using a systematic random sampling design, 4 sections of each block were selected and analyzed per animal. The mean percentage of the 8 sections of each animal was taken as the value for each rat.

Descriptive statistics data were calculated and presented graphically as means $( \pm \mathrm{SD})$ using the statistical software Statistica for Windows v. 5.0 (StatSoft Inc., Tulsa, OK, USA). In this experiment, the dependent variables were (i) blood cholesterol level and (ii) bone regeneration, while the independent variables were (i) administration route (oral or subcutaneous), (ii) drug (administration or not of simvastatin) and (iii) observation period (15 or 30 days). Data were submitted to statistical analysis by ANOVA at 5\% significance level using the statistical software Minitab for Windows (v. 13.1, 2000; Minitab Inc., State College, PA, USA).

\section{RESULTS}

\section{Blood Cholesterol Level Analysis}

Descriptive statistics data of blood cholesterol level can be seen on Figure 2. Due to insufficient plasma volume of 1 sample of groups AC30 and AT30, only 4 samples were analyzed in these groups. Mean values ranged from $48.07 \mathrm{mg} / \mathrm{dL}$ (group BC30) to $74.02 \mathrm{mg} /$ dL (group AC30); standard deviation ranged from 5.39 $\mathrm{mg} / \mathrm{dL}$ (group BT15) to $16.59 \mathrm{mg} / \mathrm{dL}$ (group AC15); and the coefficient of variation ranged from $7.30 \%$ (group BT15) to $24.38 \%$ (group AC15).

There was no statistically significant difference among the tested main effects and interactions, regarding cholesterol level. Blood cholesterol level was neither affected by administration route $(F(\mathrm{df} 1,30)=1.22$; $p=0.278)$, drug $(F(\mathrm{df1}, 30)=1.18 ; p=0.287)$, observation period $(F(\mathrm{df} 1,30)=3.73 ; p=0.063)$, nor by the interac-

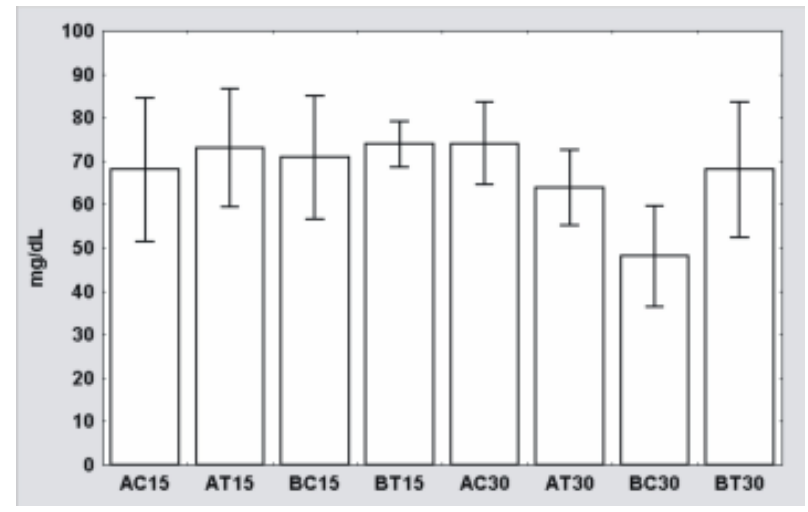

Figure 2. Means ( $\pm \mathrm{SD}$ ) of blood cholesterol level data (mg/dL). The groups did not differ significantly. A: subcutaneous administration; B: oral administration; C: control; T: treated. Observation period: 15 or 30 days. 
tion of administration route, drug and observation period $(F(\mathrm{df} 1,30)=3.81 ; p=0.06)$. Other interactions did not affect blood cholesterol level significantly either.

\section{Histomorphometrical Analysis}

Descriptive statistics data of bone regeneration on the center of the defect is shown on Figure 3. One animal of group BC30 had its right tibia fractured and was excluded from the analysis. Mean values of bone regeneration ranged from $36.7 \%$ (group AT15) to $52.9 \%$ (group BT30); standard deviation ranged from $6.5 \%$ (group BT15) to $13.7 \%$ (group BC30); and the coefficient of variation ranged from 14.29\% (group BT15) to $26.81 \%$ (group BC30).

Statistically significant difference was found only between animals sacrificed after 15 and 30 days $(F(\mathrm{df} 1,31)=7.92 ; p=0.008)$. Animals killed after 30 days had a greater percentage of bone formation (49.1 $\pm 10.4 \%$ ) than those killed after 15 days ( $40.5 \pm 8.1 \%)$ (Fig. 4). Bone regeneration was neither affected significantly by route of administration $(F(\mathrm{df} 1,31)=2.60 ; p=$ $0.117)$, by drug $(F(\mathrm{df} 1,31)=0.11 ; p=0.739)$ nor by the interaction of administration route, drug and observation period $(F(\mathrm{df} 1,31)=0.33 ; p=0.571)$. Other interactions did not affect bone regeneration significantly.

\section{Histological Analysis}

15-Day Period. Woven bone formation from the well-defined margins of lesion was seen across the

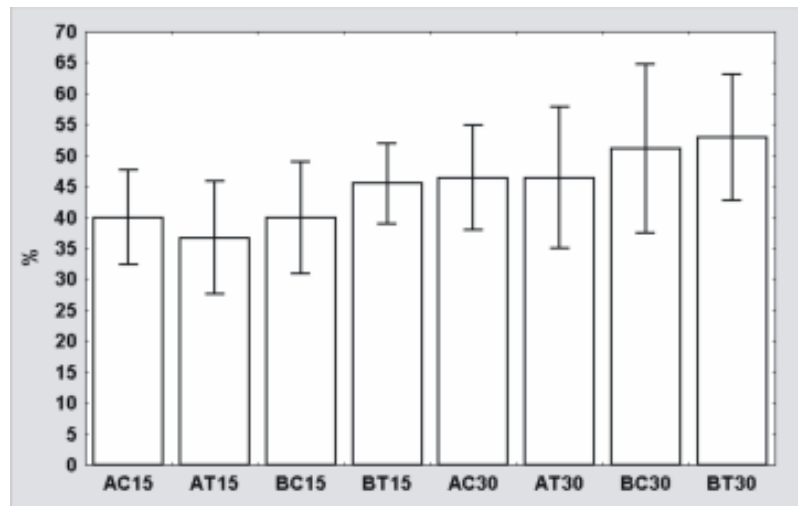

Figure 3. Means $( \pm \mathrm{SD})$ of bone regeneration data (\%) on bone defect center. A: subcutaneous administration; B: oral administration; C: control; T: treated. Observation period: 15 or 30 days. defect (Figs. 5A and 5B). In most specimens, there was linear closure of the defect by new cancellous bone (Fig. $5 \mathrm{~A})$. New bone formation was inside medullar canal and on the opposite region of the defect (Fig. 5A) in some specimens. Bone formation was originated from periosteum and mainly from endosteum. Bone remodeling was observed in preexistent bone near defect site, with subperiosteal callus formation, enclosing new bone formation and immature trabeculae delimiting connective tissue portions. A thick or slim fibrous connective tissue layer was formed over bone bridge surface, without occupying defect site (Fig. 5A). This tissue, which may correspond to periosteum in organization or surgical scar, had flattened and spindleshaped cells near new bone formation. Trabeculae bone containing numerous and large osteocytes were surrounded by flat or voluminous osteoblasts and delimited wide marrow spaces (Fig. 5B). Few multinucleated giant cells were observed over trabeculae surface, especially under periosteum.

30-Day Period. The main characteristic of sections of animals sacrificed after 30 days was a slim bone bridge across the defect, composed mainly of cortical bone, resulting in linear closure (Fig. 6A). Bone marrow and vascular connective tissue were found included in bone bridges. Bone trabeculae surrounded by osteogenic cells and delimiting bone marrow were sometimes observed inside medullar canal (Fig. 6A). New bone was composed of smaller osteocytes (Fig. 6B), arranged in a quite lamellar pattern and sometimes of large osteocytes arranged in an irregular pattern. Periosteum

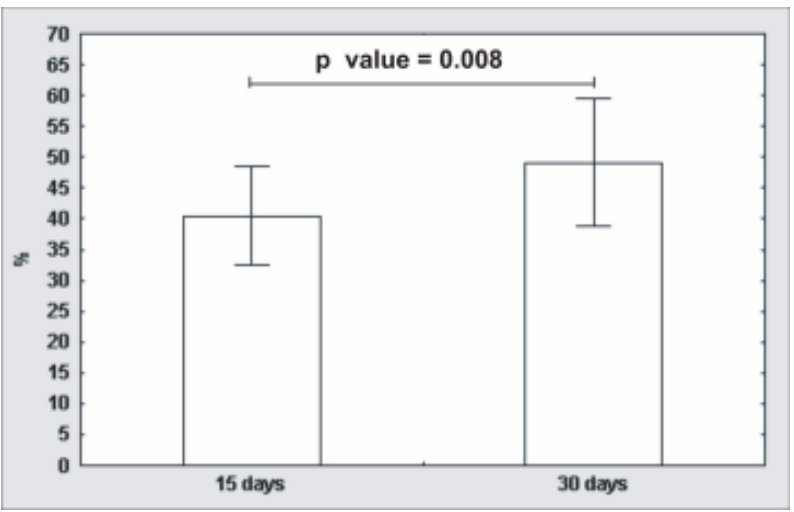

Figure 4. Means ( \pm SD) of bone regeneration data (\%) on bone defect center. The observation periods (15 and 30 days) did not differ significantly. 
and endosteum were organized most times. Reversal basophilic lines on new bone matrix (Fig. 6B) and multinucleated giant cells that were found in many sections indicated bone remodeling. Bone marrow inclusion in the margins of the defect area indicated that remodeling also occurred in old bone.

\section{DISCUSSION}

An experimental bone wound used to assess repair should be large enough to preclude spontaneous healing, because only in this situation the osteogenic potential of an implant or graft may be considered unequivocal (8). A critical size defect may be defined as the smallest size intraosseous wound in a particular bone and species that will not heal spontaneously during the lifetime of the animal. However, because most studies are of limited duration and do not extend over the entire life of the animal, the critical size defect in animal research refers to the size of a defect that will not heal over the duration of the study (9).

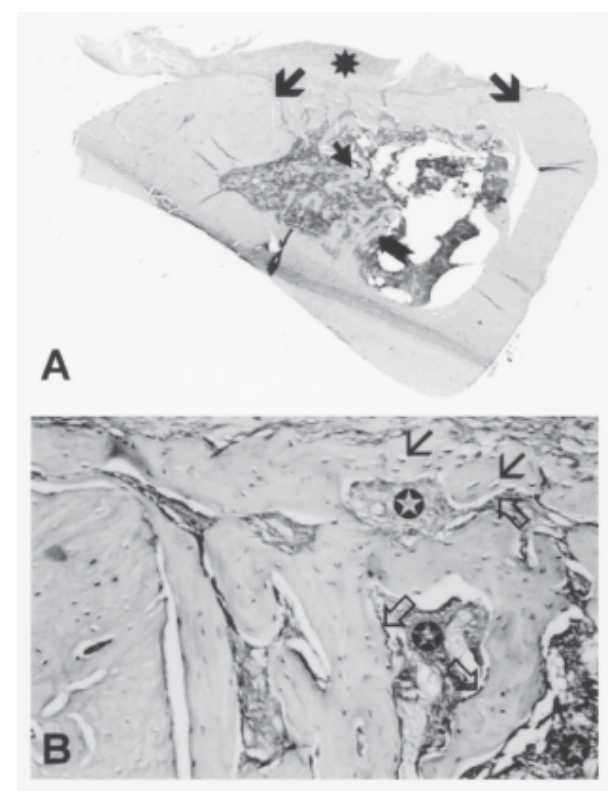

Figure 5. Histological aspect of animals sacrificed after 15 days. (A) Linear defect closure with cancellous bone. Well-defined bone defect margins $(\rightarrow$ ), bone formation inside medullar canal $(\rightarrow)$ and on the opposite region to the defect $(\Rightarrow)$. Fibrous connective tissue layer over bone bridge surface, without occupying defect site (*) (HE, X25). (B) Woven bone trabeculae with numerous and large osteocytes $(\rightarrow)$, surrounded by osteoblasts $(\leftrightharpoons)$ and delimiting marrow spaces ( $)$ (HE, X200).
Based on linear length of new bone, there was defect closure in animals sacrificed after 15 and 30 days of surgery. According to Schmitz and Hollinger's (8) critical size defect concept, in the present experiment, defect size was not critical. Nevertheless, based on cross-sectional area analysis, there was no complete healing. Actually, in all specimens, it was possible to identify the defect region and note the difference between new and old bone. There was no complete spontaneous bone regeneration in the control group, making the analysis of the osteogenic potential of simvastatin possible, under this experimental model.

There was no significant difference in blood cholesterol level related to any studied variable. Lack of hipocholesterolemic activity of statins in normal rats has been found $(10,11)$. However, studies show that statins are effective in lowering blood cholesterol in monkeys (12) and humans (13) without hypercholesterolemia.

According to Endo et al. (10), who administered mevastatin, a HMG-CoA reductase inhibitor, to rats and mice, species differences in statin efficacy in lowering

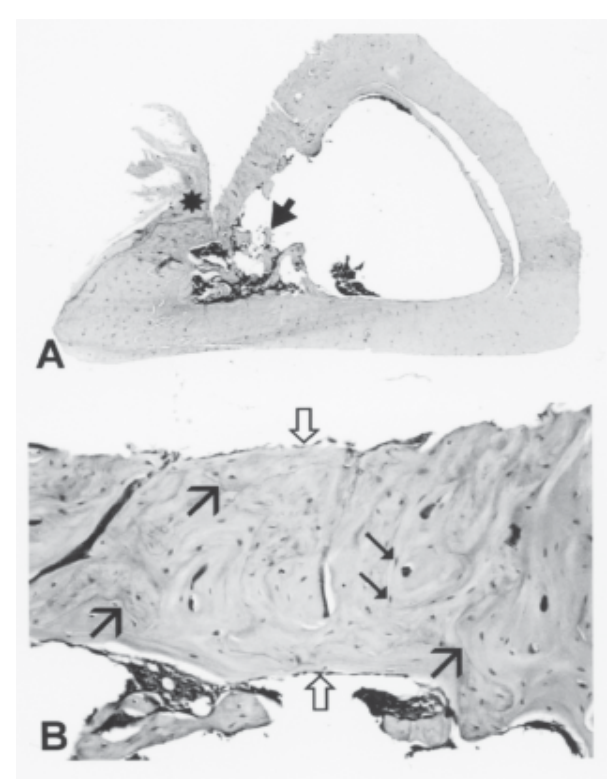

Figure 6. Histological aspect of animals sacrificed after 30 days. (A) Linear defect closure by a slim bone bridge and few trabeculae inside medullar canal $\rightarrow$ ). Fibrous connective tissue layer over bone bridge surface, without occupying defect site (*) (HE, $\mathrm{X} 25)$. (B) Cortical bone bridge, with reversal lines $(\rightarrow)$ and smaller osteocytes ( $\rightarrow$ ) than observed in specimens sacrificed after 15 days, beginning a lamellar organization. Osteogenic cells ( $)$ ) surrounding the bone bridge (HE, X200). 
the plasma cholesterol levels is secondary to the ability of certain species to metabolize plasma lipoprotein via hepatic pathways. Statins should cause a transient decrease of hepatic cholesterol. To meet this privation, an increased consumption of plasma cholesterol levels would occur in hens, dogs, monkeys and humans, while hepatic HMG-CoA reductase would be elevated in rats and mice due to their inability to catabolize plasma lipoproteins in the liver. This elevation of hepatic reductase, which overcomes statin inhibition, appears to account for the lack of effectiveness of these drugs in rats and mice. In addition, decreased excretion of bile acids in rats treated with mevastatin would partly contribute to the ineffectiveness in these animals (10).

Statistical analysis of histomorphometrical data showed significant difference related only to observation period. Increased bone healing after 30 days is a predictable result. However, there was no difference related to administration route (oral or subcutaneous) or drug (administration or not of simvastatin). Data from histomorphometrical analysis agree with those of histological analysis, which revealed difference only related to the observation period. Animals killed after 15 days showed the same morphological aspects, such as woven bone trabeculae formation and linear defect closure by new cancellous bone. Groups sacrificed after 30 days showed linear defect closure with a cortical bone bridge, smaller osteocytes and osteocytes lacunae, sometimes in a lamellar pattern, and fewer bone trabeculae, which are the result of bone remodeling.

Mundy et al. (3) reported that statins increase bone formation after subcutaneous injection of simvastatin over the skull bones of mice and after oral administration to rats, ovariectomized or not. Statin effects improving bone density and reducing risk of fractures have been documented by various studies (4). Such effects seem to be the result of the increasing production and expression of BMP-2 (3). These observations emphasize the unknown role of the mevalonate pathway in the regulation of bone formation, according to Rogers (5). Although the exact molecular mechanism by which statins increase bone formation is not known, it is possible that small GTPases, prenylated by products of the mevalonate pathway, negatively regulate expression of BMP-2. By inhibiting the mevalonate pathway and preventing the prenylation and function of small GTPases, BMP-2 expression may be stimulated, which causes increased osteoblast proliferation and, conse- quently, enhanced bone formation (5).

Although several studies have shown a beneficial effect of statins on bone $(4,14,15)$, this subject is still controversial. Van Staa et al. (16) analyzed the medical records of 81,880 patients who had fractures and concluded that the use of statins at dosages prescribed in clinical practice was not associated with a reduction in risk fracture. According to these authors (16), the lower fracture rates previously reported among statin users are most likely explained by the residual confounding effect of obesity in those analyses, and other sources of inconsistency include variations in study design. Maritz et al. (17) reported that simvastatin was unable to prevent bone loss caused by ovariectomy in rats and suggested a permissive effect for estrogens in statin action on bone. According to them (17), the contrasting results obtained in their study and those of Mundy et al. (3) may be explained by differences in statins, dosages, methods of administration, experimental animal model and design. On the other hand, another study (18) analyzed mandibular bone defect regeneration in ovariectomized and non-ovariectomized rats and found that simvastatin aided new bone formation only in ovariectomized animals.

In the present study, based on the hypothesis that statins stimulate bone formation, simvastatin did not aid defect bone regeneration, agreeing with a previous study (18) that found no effect of simvastatin on nonovariectomized rats bone healing. The effect of simvastatin on the mandibular bone defect regeneration only in ovariectomized rats is probably associated with the increase in bone density caused by the use of this medicament for osteoporosis (18). Statins stimulate bone formation in remodeling process (3), but did not stimulate bone formation in regeneration process, by oral or subcutaneous administration. A recent study (19), however, found that rat bone defects grafted with carriers of collagen matrix mixed with simvastatin solution had accelerated bone formation when compared to those without locally statin. Several hypotheses may be drawn from the results of this study, but none of them has been proven. Differences between bone remodeling and bone regeneration processes may explain the different effects of statins in these cases. Lack of selective bone targeting property of simvastatin may have been a cause of inefficacy in improving bone regeneration, in spite of subcutaneous administration. Tested doses may have been inadequate to cause a better 
bone healing. Perhaps intermittent use of high doses would stimulate bone formation more effectively than daily use of standard doses (20). Further research is required to find formulations, doses, routes and schedules of administration that optimize the effects of statins without decreasing their benefits (20) and only after these, it will be possible to state that simvastatin does not alter bone regeneration.

\section{RESUMO}

Este estudo avaliou a influência da sinvastatina, administrada por via oral ou subcutânea, na reparação de defeitos ósseos em tíbia e nos níveis de colesterol sangüíneo, em ratos. Foram realizados defeitos cirúrgicos nas tíbias direitas de 40 ratos machos, distribuídos em 4 grupos ( $\mathrm{n}=10$ ), tomando-se como base duas vias de administração e o uso ou não de sinvastatina: injeção subcutânea de sinvastatina (7 mg/kg) (grupo AT) ou apenas do veículo de suspensão da droga (grupo $\mathrm{AC}$ ), sobre a região do defeito, durante 5 dias; 20 mg/kg de sinvastatina (grupo BT) ou água filtrada (grupo BC) via oral, diariamente, durante todo o período de observação. Os animais foram sacrificados após 15 ou 30 dias, quando amostras sangüíneas foram colhidas para análise do nível de colesterol. As tíbias foram removidas e, após descalcificação e procedimentos laboratoriais de rotina, procedeuse à análise histológica e histomorfométrica. Para avaliação estatística utilizou-se ANOVA com nível de significância de 5\%. As análises histomorfométrica e histológica mostraram diferença entre os grupos apenas com relação ao período experimental $(\mathrm{p}<0,05)$, apresentando os melhores resultados os animais sacrificados em 30 dias $(\mathrm{p}<0,05)$. Quanto ao nível de colesterol sangüíneo, não houve diferença estatisticamente significante entre os grupos analisados ( $>>0,05)$. Concluiu-se que, nas condições utilizadas, a sinvastatina, administrada via oral ou subcutânea, não exerceu efeito estimulador sobre o reparo ósseo de defeitos experimentais em tíbias de ratos e não alterou os níveis de colesterol sangüíneo.

\section{ACKNOWLEDGEMENTS}

The authors would like to thank Baldacci S.A. LaboratoryBrazil for granting the medication Sinvascor.

\section{REFERENCES}

1. Lennernäs $H$, Fager G. Pharmacodynamics and pharmacokinetics of the HMG-CoA reductase inhibitors. Clin Pharmacokinet 1997;32:403-425.

2. Hamelin BA, Turgeon J. Hydrophilicity/lipophilicity: relevance for the pharmacology and clinical effects of HMG-CoA reductase inhibitors. Trends Pharmacol Sci 1998;19:26-37.

3. Mundy G, Garrett R, Harris S et al. Stimulation of bone formation in vitro and in rodents by statins. Science 1999;286:1946-1949.

4. Hatzigeorgiou C, Jackson JL. Hydroxymethylglutaryl-coen- zyme A reductase inhibitors and osteoporosis: a meta-analysis. Osteoporos Int 2005;16:990-998.

5. Rogers MJ. Statins: lower lipids and better bones? Nat Med 2000;6:21-23.

6. Huang TC, Chen CP, Wefler V, Raftery A. A stable reagent for the Liebermann-Burchard reaction. Application to rapid serum cholesterol determination. Anal Chem 1961;33:1405-1407.

7. Gray T. Quantitation in histopathology. In: Theory and practice of histological techniques. Bancroft JD, Stevens A. (Editors). 4th ed. New York: Churchill Livingstone; 1996. p. 641-671.

8. Schmitz JP, Hollinger JO. The critical size defect as an experimental model for craniomandibulofacial nonunions. Clin Orthop 1986;205:298-307.

9. Gosain AK, Song L, Yu P, Mehrara BJ, Maeda CY, Gold LI, Longaker MT. Osteogenesis in cranial defects: reassessment of the concept of critical size and the expression of TGF(beta) isoforms. Plastic Reconstr Surg 2000;106:360-371.

10. Endo A, Tsujita Y, Kuroda M, Tanzawa K. Effects of ML236B on cholesterol metabolism in mice and rats: lack of hypocholesterolemic activity in normal animals. Biochim Biophys Acta 1979;575:266-276.

11. Tsujita Y, Kuroda M, Shimada Y, Tanzawa K, Arai M, Kaneko I, Tanaka M, Masuda H, Tarumi C, Watanabe Y, Fujii S. CS-514, a competitive inhibitor of 3-hydroxy-3methylglutaryl coenzyme A reductase: tissue-selective inhibition of sterol synthesis and hypolipidemic effect on various animal species. Biochim Biophys Acta 1986;877:50-60.

12. Kuroda M, Tsujita Y, Tanzawa K, Endo A. Hypolipidemic effects in monkeys of ML-236B, a competitive inhibitor of 3-hydroxy-3-methylglutaryl coenzyme A reductase. Lipids 1979;14:585-589.

13. Tobert JA, Hitzenberger G, Kukovetz WR, Holmes IB, Jones KH. Rapid and substantial lowering of human blood cholesterol by mevinolin (MK-803), an inhibitor of hydroxymethylglutaryl-coenzyme A reductase. Atherosclerosis 1982;41:61-65.

14. Rejnmark L, Vestergaard P, Mosekilde L. Statin but not nonstatin lipid-lowering drugs decrease fracture risk: a nationwide case-control study. Calcif Tissue Int 2006;79:27-36.

15. Nakashima A, Nakashima R, Ito T, Masaki T, Yorioka N. HMG-CoA reductase inhibitors prevent bone loss in patients with Type 2 diabetes mellitus. Diabet Med 2004;21:1020-4.

16. Van Staa TP, Wegman S, de Vries F, Leufkens B, Cooper C. Use of statins and risk of fractures. J Am Med Assoc 2000;285:1850-1855.

17. Maritz FJ, Conradie MM, Hulley PA, Gopal R, Hough S. Effect of statins on bone mineral density and on bone histomorphometry in rodents. Arterioscl Thromb Vasc Biol 2001;21:1636-1641.

18. Junqueira JC, Mancini MNG, Carvalho YR, Anbinder AL, Balducci I, Rocha RF. Effects of simvastatin on bone regeneration in the mandibles of ovariectomized and on blood cholesterol level. J Oral Sci 2002;44:117-124

19. Wong RWK, Rabie ABM. Early healing pattern of statininduced osteogenesis. Br J Oral Maxillofac Surg 2005;43:46-50.

20 Cummings S, Bauer D. Do statins prevent both cardiovascular disease and fracture?[editorial] J Am Med Assoc 2000;283:3255-3257. 